\title{
Regionalization based on spatial and seasonal variation in ground-level ozone concentrations across China
}

Linjun Cheng ${ }^{1,2}$, Shuai Wang ${ }^{2}$, Zhengyu Gon ${ }^{2}, \quad$ Hong $\mathrm{Li}^{3}$, Qi Yang ${ }^{1 *}$, Yeyao Wang ${ }^{1,2, *}$

1. School of Water Resources and Environment, China University of Geosciences, Beijing 100083, China. chenglj@cnemc.cn

2. China National Environmental Monitoring Center, State Environmental Protection Key Laboratory of Quality Control in Environmental Monitoring, Beijing 100012, China

3. Lancaster Environment Centre, Lancaster LA1 4YQ, ancaster University, UK

\begin{abstract}
Owing to the vast territory of China and strong regional characteristic of ozone pollution, it is desirable for policy makers to have a targeted and prioritized regulation and ozone pollution control strategy in China based on scientific evidences. It is important to assess its current pollution status as well as spatial and temporal variation patterns across China. Recent advances of national monitoring networks provide an opportunity to insight the actions of ozone pollution. Here, we present rotated empirical orthogonal function (REOF) analysis that used on study the spatiotemporal characteristics of daily ozone concentrations. Based on the results of REOF analysis in pollution seasons for 3 year's observations, twelve regions with clear patterns were identified in China. The patterns of temporal variation of ozone in each region were separated well and different from each other, reflecting local meteorological, photochemical or pollution features. A rising trend for annual averaged of Eight-hour Average Ozone Concentrations $\left(\mathrm{O}_{3}-8 \mathrm{hr}\right)$ from 2014 to 2016 was observed for all regions, except for the Tibetan Plateau. The mean values of annual and 90 percentile concentrations for all 338 cities were $82.6 \pm 14.6 \mu \mathrm{g} / \mathrm{m}^{3}$ and $133.9 \pm 25.8 \mu \mathrm{g} / \mathrm{m}^{3}$, respectively, in 2015. The regionalization results of ozone were found to be influenced greatly by terrain features, indicating significant terrain and landforms effects on ozone spatial correlations. Among the 12 regions, North China Plain, Huanghuai Plain, Central Yangtze River Plain, Pearl River Delta and Sichuan Basin were realized as priority regions for mitigation strategies, due to their higher ozone concentrations and densely population.
\end{abstract}

\section{Keywords:}

Ozone 
Spatiotemporal variability

REOF

Regionalization

\footnotetext{
* Corresponding Author. E-mail: yeyaowang@163.com (Yeyao Wang); yq@ @ugb.edu.cn (Qi Yang)

** The authors contribute equally to this article.
}

\section{Introduction}

Increased ground-level ozone concentrations are the cause of major environmental concern. Ground-level ozone has been considered the most phytotoxic air pollutant due to its significant damage to the plants and rising trend of concentrations at regional scale (The Royal Society, 2008). Urbanization, industrialization, high-speed propulsion, and atmospheric emissions of a large numbers of active substances, are causing many parts of China to face severe ozone concentrations in summer and autumn, linked to photochemical reactions (Tang et al., 2006; Zhang et al., 1998; Shao et al., 2006; Streets et al., 2007). Such problems have become regional and more complex over time (Zhang et al., 1998), with severe episodes occurring more frequently. In some cities, ozone has levels higher than the national standard around $20 \%$ of the time; while in other areas, ozone maximum hourly concentrations exceed the European alarm level (240 ppb) for heavy pollution (Chen et al., 2013; Yang et al., 2012; Huang et al., 2011; Huang et al., 2013; Zhang et al., 2009; Zhang et al., 2004). The ground-level ozone associated with some other pollutants, which can induce severe diseases. In animal and human studies, repeated exposures in ozone have been shown to lead to airway inflammation and affect lung function (Aris et al., 1993; Coleridge et al., 1993). Published studies have indicated that air ozone concentrations in an average of $40 \mathrm{ppb}$ have significantly reduced the yield of major food crops (including wheat, rice, soybean, potato) by about $10 \%$ compared with ozone-free air (Feng and Kobayashi, 2009). It can be deduced that human health and food security are being or has already been threatened by ozone concentration and the damage will continue in the future.

China is the third largest country in the world with a land area of 9.6 million square 
kilometers and a north-south cross-latitude of nearly 50 degrees. The meteorological condition is complex and varied, and the terrain is high in the west and low in the east. Therefore, the impacting factors on ozone generating, such as radiation or humidity, were very different across the country. Since 1999, the pollution status, temporal variation pattern, and health effects of ozone have been investigated in several metropolitans in China (Wang and Li, 2014; Wei and Zheng, 2006; Yin et al., 2015; Zhang et al., 2013; Su et al., 2011; Chen and Wang, 2015; Liang et al., 2014; Chen et al., 2010). However, these studies are then limited to spatial range, and there is no information on the characteristics of the national ozone pollution distribution. Administrative measures implemented by the Ministry of Environmental Protection (MEP) to respond to ozone pollution were initiated in 2013. As result, a real-time on line ground ozone observation system was established, that monitoring makes it possible to conduct a detailed studies on the spatiotemporal characteristics of ozone pollution in China first time. Given the significant regional contribution to local ozone pollution (Wang et al., 1998), regional-scale pollution prevention measures should be adopted to effectively control air pollution by Chinese government. The MEP has identified several key prevention and control areas for ozone pollution, which based on their level of economic development and pollution. They are Beijing-Tianjin-Hebei region, Yangtze River Delta, Pearl River Delta and Chengdu-Chongqing region. However, the spatiotemporal variability of ozone levels was not considered, when identifying these regions. Several studies (Zhang et al., 2012; Duan et al., 2008) have attempted to build air pollution divisions of China, based on the spatiotemporal characteristics of visibility or the air pollution index (API), by empirical orthogonal function (EOF) analysis. However, such studies have a limited scope, and have not dealt with the regionalization of datasets for one specific air pollutant, such as ozone in China.

The objectives of this work were to find the spatiotemporal characteristics of ozone pollution on a national scale, and help developing regionally prevention strategies. The method of rotated empirical orthogonal function (REOF), which has been widely used in meteorological science, was applied in this study. This method could decompose the time series of spatial variables into several orthogonal modes and corresponding time coefficients. The spatial distributions of modes reflect the spatial correlations between variables, which gives insights for regionalization of cities. The time coefficients of each mode represent the 
temporal variation pattern of ozone for those cities. The results of this study will improve the current understanding of the spatial distributions, seasonal trends, and regional situation of ozone within China. This helps policy makers to develop targeted prevention and control measures based on ozone pollution characteristics over different regions.

\section{Methods}

\subsection{Datasets}

Datasets include ozone monitoring data, topographic data and meteorological data. The ozone monitoring datasets were provided by the China National Environmental Monitoring Center (CNEMC). We used ozone daily maximum 8-hour sliding average $\left(\mathrm{O}_{3}-8 \mathrm{hr}\right)$ concentration as ozone concentration to record from 161 cities in 2014, and 338 cities in 2015 and 2016, yielding more than 242,000 individual data points. Value of a city is average of the concentrations measured at all urban sites of this city. Ozone monitoring data was collected by continuous automated equipment, the measure principles were Ultraviolet photometer or Differential Optical Absorption Spectroscopy. All the equipments used had passed the applicability test of the CNEMC.

Topographic data were obtained from Global 30 Arc-Second Elevation dataset, which is supplied by United States Geological Survey. The spatial resolution for topographic data was $0.0833^{\circ} \times 0.0833^{\circ}(1 \mathrm{~km}$ resolution $)$.

Daily meteorological parameters records including temperature, relative humidity, wind speed, atmosphere pressure and Sunshine duration were from China Meteorological Agency.

\subsection{Computational method}

To explore the spatiotemporal variations in ozone across China, data from these 338 cities were geographically grouped into seven divisions, namely North China (Beijing, Tianjin, Shanxi, Hebei, Inner Mongolia), Northeast China (Heilongjiang, Jilin, Liaoning), Northwest China (Shaanxi, Gansu, Qinghai, Ningxia, Xinjiang), East China (Shanghai, Jiangsu, Zhejiang, Anhui, Jiangxi, Shandong, Fujian), Central China (Henan, Hubei, Hunan), South China (Guangdong, Guangxi, Hainan), and Southwest China (Sichuan, Guizhou, Yunnan, Chongqing, Tibet). Regional ozone concentrations for each division were calculated as means 
of ozone concentrations for all cities located in that division.

To study the spatiotemporal variation of ozone, the REOF analysis was used to investigate any significant spatial correlations among different cities. This method has been successfully used for regionalization of precipitation and visibility in China (Zhang et al., 2012; Chen et al., 2010; Chen et al., 2011; Yang and Xu, 1994), but has seldom been used to undertake regionalization of $\mathrm{O}_{3}$. By $\mathrm{REOF}$ analysis, several main orthogonal temporal variation patterns were extracted from temporal variations of $\mathrm{O}_{3}$ across all cities. Then the time series of $\mathrm{O}_{3}$ in each city could be approximately represented by superposition of these orthogonal signals (called modes) and corresponding coefficients. The coefficients reflected the spatial distributions of these modes, which meant that areas with high coefficients shared common $\mathrm{O}_{3}$ variation patterns. Generally, a coefficient of 0.6 was used to distinguish high correlated areas. The mathematical model of REOF and solve method has been explained in literature (Wang et al., 2015; Richard and Dean, 2001).

\section{Results and discussion}

\subsection{Spatiotemporal variation of ozone in China}

\subsubsection{Spatial distribution of ozone}

The annual and 90 percentile of $\mathrm{O}_{3}-8 \mathrm{hr}$ concentrations in 338 cities across China is spatially heterogeneous (Fig.S-1). The annual ozone concentrations ranged from 36.9 to $118.2 \mu \mathrm{g} / \mathrm{m}^{3}$ while the 90 percentile concentrations ranged from 62.0 to $202.7 \mu \mathrm{g} / \mathrm{m}^{3}$. The mean values of annual and 90 percentile concentrations for all 338 cities were $82.6 \pm 14.6 \mu \mathrm{g} / \mathrm{m}^{3}$ and $133.9 \pm 25.8 \mu \mathrm{g} / \mathrm{m}^{3}$, respectively. Of all cities, 35 have annual $\mathrm{O}_{3}-8 \mathrm{hr}$ concentrations over than $100 \mu \mathrm{g} / \mathrm{m}^{3}$ and 54 have 90 percentile concentrations over than $160 \mu \mathrm{g} / \mathrm{m}^{3}$. The North China, Central China and East China had higher $\mathrm{O}_{3}$ levels than other regions. Specifically, Beijing and several urban areas in Shandong had the highest ozone concentrations in China. This may be attributed to large amount of precursor emissions in these high population density regions. The regional average $\mathrm{O}_{3}-8 \mathrm{hr}$ concentrations in different geographic divisions are summarized in Table 1. The 90 percentile concentrations in Central China, North China and East China have values exceeding $140 \mu \mathrm{g} / \mathrm{m}^{3}$ while in other regions were less than $130 \mu \mathrm{g} / \mathrm{m}^{3}$. The annual 
averaged $\mathrm{O}_{3}-8 \mathrm{hr}$ concentrations were linearly correlated with 90 percentile concentrations for all divisions except for Northwest China. Urban areas in Tibetan Plateau had higher annual $\mathrm{O}_{3}-8 \mathrm{hr}$ concentrations but lower 90 percentile concentrations compared to mid-eastern China, indicating the different statistical characteristics of ozone concentrations between plain and plateau areas. Areas with relatively low ozone concentrations are located in Southwest China, South China and part of Northwest China. Here, 14 cities had annual averaged concentrations lower than $55 \mu \mathrm{g} / \mathrm{m}^{3}$. These less polluted cities have relatively lower anthropogenic emissions and the local meteorological condition may also be not favorable for generating of ozone.

The spatial distributions of quarterly averaged ozone concentration in different seasons are shown in Fig.S2. The averaged ozone concentrations for spring, summer, autumn, and winter were $93.5 \pm 21.6,102.6 \pm 26.1,77.5 \pm 17.9$, and $56.3 \pm 15.0 \mu \mathrm{g} / \mathrm{m}^{3}$ respectively. The highly polluted cities (with seasonal ozone concentrations above $100 \mu \mathrm{g} / \mathrm{m}^{3}$ ) represented $54.4 \%$ and $0.6 \%$ of the total 338 cities in summer and winter, respectively. Ozone pollution is significantly higher in summer than winter.

The Air Quality Guideline given by WHO for $\mathrm{O}_{3}-8 \mathrm{hr}$ is $100 \mu \mathrm{g} / \mathrm{m}^{3}$, this concentration will provide adequate protection to public health, though some health effects may occur below this level. Ozone concentrations in some cities have exceeded the guideline, especially in spring and summer. How to take effective measures to control the intensification of ozone pollution to protect human health has become a top priority.

\subsubsection{Seasonal patterns of ozone concentrations}

The patterns of monthly averaged $\mathrm{O}_{3}-8 \mathrm{hr}$ for different divisions were similar. All of them showed an increasing trend from January to May, followed by persistent high levels during May to October, then decreased sharply from October to December (Fig.1). The highest monthly averaged $\mathrm{O}_{3}-8 \mathrm{hr}$ occurred from May to August in all geographic divisions. The most seriously contaminated regions in summer months were in North China, Northeast China, East China and Central China. The summer monthly averaged $\mathrm{O}_{3}-8 \mathrm{hr}$ in these regions were all above $100 \mu \mathrm{g} / \mathrm{m}^{3}$. The most seriously polluted region was North China, having monthly averaged $\mathrm{O}_{3}-8 \mathrm{hr}$ above $100 \mu \mathrm{g} / \mathrm{m}^{3}$ from May through to September. Meanwhile, winter monthly averaged $\mathrm{O}_{3}-8 \mathrm{hr}$ were much lower, with concentrations in the range of $43-55 \mu \mathrm{g} / \mathrm{m}^{3}$ 
for all divisions. The seasonal patterns of ozone can be attributed by the seasonal variation in meteorological conditions, precursor emissions, and photochemical reactions.

Trends in annual and seasonal averaged $\mathrm{O}_{3}-8 \mathrm{hr}$ in Beijing, Shenyang, Shanghai, and Chongqing are summarized in Fig.2. The annual averaged $\mathrm{O}_{3}-8 \mathrm{hr}$ in Beijing, Shenyang and Shanghai have had an overall upward trend from 2008 to 2015. The north and east China represent the population centers of China, with well developed industry and agriculture. Thus, the higher ozone concentrations over these regions may be a result of an increase in the emissions of ozone precursors in these regions. Especially in summer, strong solar radiation and higher temperatures exacerbate the atmospheric photochemical reactions.

The ozone concentrations of Shanghai was uncharacteristically high in autumn, which has been frequently reported (Cai et al., 2010; Geng et al., 2007; Wang, 2015). It reflects the local synoptic flow pattern, which is the product of the interaction of the East Asian monsoon, tropical cyclones, and the land-sea breezes over the Yangtze River Delta region.

In the summer of 2012, ozone concentrations of four cities except Shanghai decreased markedly, but in the following winter, ozone concentrations in all four cities increased sharply. This may due to the unusual climatic conditions that occurred in 2012 (Wang et al., 2013). With the effect of anomalies in ocean and atmospheric circulation in the winter of 2011/2012, and a La Nina event in March 2012, warmer than normal spring and summer, and colder than normal autumn occurred in China in 2012, causing uncharacteristic pollution trends.

\subsection{Regionalization of ozone}

\subsubsection{Results of rotated empirical orthogonal function analysis}

To explore the spatiotemporal variation of ozone in more detail, the REOF analysis was conducted for both the whole year and the four seasons of the year. As shown of variance contributions in Fig.3a for different scenarios, the accumulated variance proportion ranged from $86.6 \%$ (all seasons) to $93.3 \%$ (summer). In spring, winter and whole year scenarios, there are one or two modes with variance proportion of nearly $30 \%$, implying that there are large areas with similar variations during these scenarios. In contrast, more modes with evenly variance proportions were extracted in summer and autumn scenarios, indicating that there is diverse cause for the variation of ozone concentration. By using inverse distance weight 
method, the spatial distributions of the modes in different scenarios are shown in Fig.4.

As can be seen in Fig.4, the highly correlated areas in different scenarios were markedly different from each other. In spring (March to May), a highly correlated area had covered North China, Northeast China and part of Northwest China. There were also some other highly correlated areas in middle Yangtze River Plain, Yungui Plateau and Guangdong province. However, the highly correlated areas had changed markedly from spring to summer, especially for the largest one. More scattered regions were distinguished in mid-eastern China for both summer and autumn scenarios. In the case of winter, two highly correlated areas appeared in mid-eastern China. The proportion of some modes is too large and cannot be used to distinguish the pollution variance pattern in different areas very well.

Some explains may be reasonable for this phenomenon. There is an increasing trend of ozone from March to May for nearly all divisions, this persistent increasing trend, which has been exhibited by many cities, may be captured by REOF as a strong signal in spatiotemporal field. Therefore the large mode extracted during spring may just represent this increasing trend of ozone in corresponding areas. For the whole year scenario, there is also a common monthly trend in all divisions, resulted a mode with variance contribution over $30 \%$. It can be said that the spring, winter and whole year scenarios were governed by some national monthly variation of ozone and failed to reflect local daily variation. During summer and autumn, the daily variation is more significant than monthly variation. Hence it is possible to obtain detailed spatial correlations during these seasons. What's more, ozone pollution occurred intensively in summer and autumn, the spatial distributions of extracted modes in summer and autumn (Fig.4b, c) could be used for developing practical mitigation strategies. Hence, we divided the years 2014 and 2015 into an ozone pollution season (May-Oct) and a non-pollution season (Jan-Apr and Nov-Dec) to explore this idea. Regionalization based on these periods shows that the accumulated variance contributions of the extracted modes for the pollution season are distributed more evenly (Fig.3b). It suggests this classification is helpful to distinguish changes of patterns in different areas, as described in more detail below.

\subsubsection{Regionalization of ozone in 2015}

The REOF analysis for the pollution season in 2015 had 43 modes, accounting for $88.5 \%$ of 
the total variance. The largest 19 modes accounted for $71.1 \%$ of the total variance. The spatial distributions of 19 modes (1-18 and 26), together with corresponding temporal variation curves, are shown in Fig.5 and Fig.S3. The areas covered by contours with orange and red colors represent high spatial correlation areas for that mode. It can be seen that the high correlation area for each mode are different from each other, which give insights for regionalization of $\mathrm{O}_{3}$.

Mode 1 has high correlation areas in North China Plain and part of Northeast China; these areas include the Beijing-Tianjin area, Hebei, Shandong, Shanxi, Inner Mongolia, Jilin, and Liaoning (Fig.5a). The terrain in this area is relatively flat compared with hilly and plateau landforms in the west. The high correlation area does not extend to Heilongjiang province in the north. In fact, there is another mode extracted in that region (mode 14).

The high correlation areas of mode 2 covered parts of Henan, Shandong and Anhui provinces encompassing the Huanghuai Plain region (Fig.5b). The terrain of this high correlation area is governed by plain and is also surrounded by hilly landform. The dense contours in the west and south indicated significant decrease of spatial correlation in surrounding hilly area.

Mode 3 has high correlation areas in Hubei, Hunan and Jiangxi provinces (Fig.5c). The areas covered by mode 3 are adjacent to mode 2 and 4 . These areas were surrounded by Nanling Mountains, Wuling Mountains and Dabie Mountains. Dense contours were also observed in these mountainous areas.

Mode 4 is centered on south China, with high loading coefficients in Guangdong and Fujian (Fig.5d). The high correlation areas of mode 4 are slightly different from the Pearl River Delta region, which includes Guangdong only. There are dense contours across Wuyi Mountains and Nanling Mountains in the north.

Mode 5 is the Yangtze River Delta Plain, which includes Jiangsu, Zhejiang, Shanghai, and a few cities of Anhui (Fig.5e). Aside from the hilly terrain in Zhejiang, this region mostly comprises plains. The economy is very developed and has a high population density.

Mode 6 is the Sichuan Basin (Fig.5f), an area surrounded by mountains. Here, the effect of topography is clear, where weakened contours in the surrounding mountains show an obvious decrease in spatial correlation. 
The highly correlated areas for modes 7 to 18 and 26 (Fig.S3 (h-g)) were found to be located in Yungui Plateau, Xinjiang, Guanzhong Plain, Qiantao Plain, Heilongjiang, Tibetan Plateau, and Hainan respectively.

These high correlation areas in Fig.5 and Fig.S3 are found to have relatively homogeneous terrains, with borders where terrain features change significantly. This topographic effect reflects near-surface air flow and meteorological conditions. Some studies had shown the topographic effects on air convection, winds, precipitation and aerosols components (Xiao and Wu, 1995; Sharman and Wurtele, 2004; Zhao et al., 2012; Smith and Barstad, 2004; Hand et al., 2014). Therefore we surmise that a regionalization based on ozone could be more appropriately determined through use of spatial distribution of the modes as well as topographic information. Given these considerations, 12 regions for $\mathrm{O}_{3}$ pollution prevention were identified and 6 of them comprise some sub-regions (Fig.6). The details can be obtained by supporting materials.

Surprisingly the regionalization results in Fig.6 were similar with other researcher's results although different pollutants or index were used by REOF. For example, Wang divided Mid-Eastern China into 10 regions based on the $\mathrm{PM}_{2.5}$ concentrations of 161 cities in 2014 (Wang et al., 2015); Zhang obtained 9 regions and 18 sub-regions using visibility datum (Zhang et al., 2012). Duan has given a result of 10 regions using API index (Duan et al., 2008). These results show that the diffusion and distribution of air pollution is highly correlated with terrain conditions.

The average and 90 percentile concentrations of $\mathrm{O}_{3}-8 \mathrm{hr}$ in the pollution season for each region in year 2015 were estimated (Table 2). It can be seen that North China Plain, Huanghuai Plain and East China have relatively higher ozone levels compared to other regions. All these regions are population dense areas with high rate of economic growth, causing large amount of precursor emissions. In east China, there are many petrochemical and organic chemical industries, which output high emissions of volatile organic compounds.

In order to verify whether the regionalization is reasonable, we choose the base city with the largest absolute value of the modes in a region, and make Pearson correlation coefficient test between the base city and other cities in the same or different region (Chen et al., 2011). The results (Table 3) show that the correlation coefficient of two cities in the same region is 
higher than two cities from different regions. So the regionalization results reflected the actual spatial correlations of $\mathrm{O}_{3}$ across China.

\subsubsection{Temporal variation of the modes}

The time coefficients of each mode are orthogonal with each other. These coefficients show the temporal variations of ozone in each mode and are influenced by meteorological conditions, photochemical reactions and precursor emissions, which were characterized with local features in that region. Fig.5 and Fig.S3 shows the time coefficients of each mode on the right together with their linear trend and six order polynomial fitting curves. These curves provide important information for understanding the temporal variation patterns of ozone levels. As the precursor emissions are relatively stable during a short period, these fluctuated coefficients are more likely to be influenced by variation of meteorological conditions.

The time coefficients of North China Plain (mode 1) show the ozone concentration peak emerged in Jun-Aug, and markedly decreases in September, having a downward trend overall. During summer, Ozone pollution in the North China Plain is linked to anthropogenic pollution emissions and strong solar radiation, producing serious photochemical smog. This period has the strongest sunshine and the highest temperature throughout the year. Ozone concentration began to decline sharply from August, corresponding well with the rainy season due to East Asian Monsoon in late summer and early autumn. This downward trend has also been observed for other regions in northern China, e.g., Huanghuai Plain (mode 2), northern Xinjiang (mode 8), southern Xinjiang (mode 15) and southern Gansu (mode 18). In contrast, the time coefficients of south China (mode 4) and central Yangtze River Plain (mode 3) show an upward trend, having more severe ozone pollution in autumn than in summer. It is believed that the evolution of East Asian Monsoon system may play an important role for this phenomenon. The prevailing clean south winds and precipitation during early summer caused lower ozone level in South China, while north wind in autumn brings inland air pollution from north, causing more serious ozone pollution in autumn.

It is interesting that although the linear trend of Huanghuai Plain (mode 2), Central Yangtze River Plain (mode 3) and Yangtze River Delta region (mode 5) are different, they are all characterized by a valley of ozone in summer with two peaks in spring and autumn. This may due to the effect of the plum rain season in Jun-Jul, most of the time in the rainy weather, less 
sunshine, more atmospheric humidity, resulting in low atmospheric ozone concentration.

The time coefficients for Sichuan Basin (mode 6) reveal that ozone pollution is a little different from those of other regions, which have 2 valleys. The valleys in May and September correspond well with rainy seasons in the Basin, namely spring rain and autumn rain over Southwest China (Jin, 2013; Bai and Dong, 2004). To explore any possible factors for this variation, meteorological parameters including sunshine duration, temperature, relative humidity, atmosphere pressure and wind speed were compared with time coefficients by Pearson correlation coefficient and stepwise regression technique. The time coefficients were found to be significantly correlated with all above parameters, with Pearson correlation coefficient $0.661,0.527,-0.431,-0.304$ and 0.275 respectively. Sichuan Basin was surrounded by mountains and plateau and there are poor atmospheric diffusion conditions. The high AOD (aerosol optical depth) values make this region to receive less solar radiation (Liu et al., 2014; Luo et al., 2012). The special climate characteristics and geographical features in the basin may contribute greatly for its unique variation pattern of ozone (mode 6). Results of stepwise regression show that the sunshine duration is the key parameter for variation of time coefficients in Sichuan Basin.

The time coefficients of Yungui Plateau (mode 7) also exhibit unique trend compared to other areas. Ozone pollution is lighter from May to October, but high in spring and late autumn. The Pearson correlation coefficients between time coefficients and meteorological parameters were $0.693,0.289,-0.793,-0.200$ and 0.449 respectively. Results of stepwise regression show that the humidity plays a more important role in Yungui Plateau. As sunshine duration is more abundant in Yungui Plateau, it may not play as such an important role as in Sichuan Basin.

\subsubsection{Annual variability of regionalization}

To verify the reliability of $\mathrm{O}_{3}$ regionalization in Fig.6, extra REOF analysis were conducted based on pollution season datasets in different years and spatial scopes. The REOF results for 161 cities in 2014 and 2015 were shown in Fig.7a, b, and the REOF results for 338 cities in 2015 and 2016 were shown in Fig.7c, d. It can be seen that there are some annual variabilities between different years although the same city list were used. For example, the high correlation areas of Middle Yangtze River Plain and Sichuan Basin in 2014 were not as 
significant as that in 2015. Compared with 2015, the high correlation areas in Middle Yangtze River Plain and Huanghuai Plain were larger in 201ㅁ․ In spite of these differences, the results shown in different scenarios still have many similarities, the North China Plain (region I), South China region (region IV), East China region (region V) and Yungui Plateau (region VII) were all identified in all scenarios. Huanghuai Plain (region II), Middle Yangtze River Plain (region III) and Sichuan Basin (region VI) were distinguished in 3 scenarios. Therefore, the regionalization results in Fig.6 were still reliable. As the density of cities may affect the REOF results, there may be some biases in Fig.6 caused by uneven distribution of the monitored cities. For example, when only 161 cities were used in REOF analysis in 2015 (Fig.7b), the Huanghuai Plain region (region II) were not extracted compared to Fig.7c when densely cities were used. It indicated that the regionalization results prefer to locate at urban agglomerations. The more advanced the local economy, the more densely populated the region and the greater the density of the cities. This also results in more concentrated and severe environmental pollution. These may partly explain the spatial distribution of ozone pollution.

\subsubsection{Ozone concentration trends in different regions}

Ozone concentration trends in different regions for pollution season of 2014 to 2016 can be seen in Fig.8. All regions showed a rise in ozone concentration, except for Region XI: Tibetan Plateau. Regions III, V, VI, VIII, IX, X, and XII had ozone concentrations that increased steadily per year. Likewise, national ozone pollution increased significantly in 2016. It is important to note that Regions VII and XII are not usually considered to be ozone pollution areas, but had increased ozone concentration over this period. This may be related to strong solar radiation and high temperatures, leading to serious pollution caused by photochemical reactions.

\section{Conclusions}

The general analysis of spatiotemporal distribution of ozone across China presented here indicates ozone concentrations were geographically heterogeneous for urban areas. The mean values of annual and 90 percentile concentrations for all 338 cities were $82.6 \pm 14.6 \mu \mathrm{g} / \mathrm{m}^{3}$ and 
$133.9 \pm 25.8 \mu \mathrm{g} / \mathrm{m}^{3}$, respectively, in 2015 . Regionalization based on these periods shows that the accumulated variance contributions to the extracted modes for the pollution season are distributed more evenly. It is very effective in distinguishing changes of patterns in different areas. Major ozone pollution regions were located on the North China Plain, the Huanghuai Plain, the East China, the Sichuan Basin, the Guanzhong Plain and the Qiantao Plain. Based upon pollution seasonal datasets by the REOF analysis for 2015, we divided China into twelve regions. This approach may be suitable for ozone pollutant regional characterizations. We analyzed the time coefficient of different modes: some modes had an overall downward trend; some modes had one or more obvious peaks, while other modes showed an increase over the study period. This means that temporal variation features of ozone concentration is consistent in the same mode. The ozone concentrations in pollution seasons for all regions rose, except for the Tibetan Plateau over the period from 2014 to 2016. Regional ozone patterns were found to correspond well with terrain characteristics, indicating significant topographic control of spatial correlations in ozone variations. Given that regionalization was influenced by seasonal changes in meteorological condition, mitigation measures based on seasonal features maybe more appropriate for some regions, especially for the North China Plain and the Yangtze River Delta region. Among the 12 regions, the North China Plain, Huanghuai Plain, Central Yangtze River Plain, Pearl River Delta, and Sichuan Basin regions should be considered as high priority regions for pollution control, because the highest ozone concentrations and dense pollutions were found in these areas. The study revealed ozone regionalization features in China. It provides evidences for cost-effective strategies in controlling ozone pollution in China.

\section{Acknowledgements}

This work was supported by the Special Funds of the State Environmental Protection Public Welfare Industry (No. 201509001, 201509002), the National Key Research and Development Program of China (No. 2016YFC0201800) and the National Major Scientific Instruments and Equipment Development Projects of China (No. 2011YQ120024).

\section{Appendix A. Supplementary data}




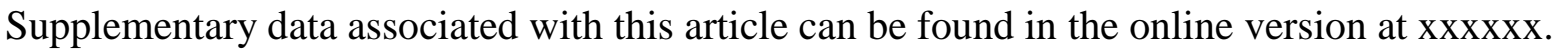

\section{References}

Aris, R.M., Christian, D., Hearne, P.Q., Kerr, K., Finkbeiner, W.E., Balmes, J.R., et al. 1993. Ozone induced airway inflammation in human subjects as determined by airway lavage and biopsy. Am. Rev. Respir. Dis. 148:1363-1372.

Bai, H.Z., Dong, W.J., 2004. Climate features and formation causes of autumn rain over southwest China. Plateau Meteorology. 23(6):884-889. (in Chinese)

Cai, C.J., Geng, F.H., Tie, X.X., Yu, Q., An, J.J. 2010. Characteristics and source apportionment of VOCs measured in Shanghai, China. Atoms Environ. 44:5005-5014.

Chen, H., Wang, X.S., 2015. Ozone Source Apportionment of Typical Photochemical Pollution Episodes in the Pearl River Delta in Autumn. Acta Scientiarum Naturalium Universitatis Pekinensis. 51: 620-630. (in Chinese)

Chen, P.F., Quan, J.N., Zhang, Q., Tie, X.X., Gao, Y., Li, X., et al. 2013. Measurements of vertical and horizontal distributions of ozone over Beijing from 2007 to 2010. Atoms Environ. 74: 37-44.

Chen, R.J., Chen, B.H., Kan, H.D., 2010. Health impact assessment of surface ozone pollution in Shanghai. China Environmental Science. 30(5): 603-608. (in Chinese)

Chen, Y.Y., Chen, N., Wang, S.G., Qian, Z.A., Mu, J.H. 2010. Temporal and spatial change features of precipitation over China-Mongolia arid- and semiarid-areas (I): Annual rainfall feature and May September one REOF analysis. Plateau Meteorology. 29(1): 33-43.(in Chinese)

Chen, Y.Y., Chen, N., Qian, Z.A., Wang, S.G. 2011. Temporal and spatial change features of precipitation over CMASA (II): Synthetical climate subregions of the CMASA and further analyses of periodic change of precipitation in its various ones. Plateau Meteorology. 30(1): 13-21. (in Chinese)

Coleridge, J.C., Coleridge, H.M., Schelegle, E.S. 1993. Acute inhalation of zone stimulated bronchial C-fibers and rapidly adapting receptors in dogs. J. Appl. Physiol. 74:2345-2352.

Duan, Y.S., Wei, H.P., Fu, Q.Y., Gao, S., Huang, R., Huang, Y.W. 2008. Regional spatio-temporal mode differences of air pollution index of key environmental protection 
cities in China. Acta Scientiae Circumstantiae. 28(2): 384-391. (in Chinese)

Feng, Z., Kobayashi, K., 2009. Assessing the impacts of current and future concentrations of surface ozone on crop yield with meta-analysis. Atmos. Environ. 43:4510-1519.

Geng, F.H., Zhao, C.S., Xu, T., Lu, G.L., Tie, X.X. 2007. Analysis of ozone and VOCs measured in Shanghai: A Case Study. Atmos. Environ, 41:981-1001.

Hand, J.L., Schichtel, B.A., Malm, W.C., Pitchford, M., Frank, N.H. 2014. Spatial and seasonal patterns in urban influence on regional concentrations of speciated aerosols across the United States. J. Geophys. Res. 119: 12832-12849

Huang, C., Chen, C.H., Li, L., Cheng, Z., Wang, H.L., Huang, H.Y., et al. 2011. Emission inventory of anthropogenic air pollutants and VOCs species in the Yangtze River Delta region, China. Atmos Chem Phys. 11: 4105-4120.

Huang, J., Zhou, C.H., Lee, X.H., Bao, Y.X., Zhao, X.Y., Fung, J., et al. 2013. The effects of rapid urbanization on the levels in tropospheric nitrogen dioxide and ozone over East China. Atmos Environ. 77: 558-567.

Jin, X., 2013. Study of Diurnal Cycle of Precipitation over the Sichuan Basin: Characteristics and its Causes. Chinese Academy of Meteorological Sciences, 17-18. (in Chinese)

Liang Y.X., Yin K.H., Hu, Y.T., Liu, B.Z., Liao, R.E., Yan, M. 2014. Sensitivity analysis of ozone precursor emission in Shenzhen, China. China Environmental Science. 34(6): 1390-1396. (in Chinese)

Liu, C., Gao, Y.H., Yi, J., Yang, S.Q., Ni, B.S., Cheng, M. 2014. An MODIS-Based analysis of Spatio-Temporal variations of aerosol optical depth in southwest of China. Journal of Southwest University (Natural Science Edition). 36(5):1-9. (in Chinese)

Luo, Y.X., Chen, J., Zheng, X.B. 2012. Climatology of aerosol optical depth over China from recent of MODIS remote sensing data. Ecology and Environmental Sciences. 21(5):876-883. (in Chinese)

Richard, A.J., Dean, W.W., 2001. Applied multivariate statistical analysis (4th edition). (LU X, Trans.). Tsinghua University press. Beijing. 388-414. (in Chinese)

Shao, M., Tang, X.Y., Zhang, Y.H., Li, W.J. 2006. City clusters in China: Air and surface water pollution. Front. Ecol. Environ. 4(7): 353-361.

Sharman, R.D., Wurtele, M.G., 2004. Three-dimensional structure of forced gravity waves 
and lee waves. J. Atmos. Sci. 61: 664-681.

Smith, R.B., Barstad, I., 2004. A linear theory of orographic precipication. J Atmos Sci. 61: 1377-1391.

Streets, D.G., Fu, J.S., Jang, C.J., Hao, J.M., He, K.B., Tang, X.Y., et al. 2007. Air quality during the 2008 Beijing Olympic Games. Atmos. Environ. 41(3): 480-492.

Su, T.C., Chen, S.Y., Chan, C.C., 2011. Progress of ambient air pollution and cardiovascular disease research in Asia. Prog Cardiovasc Dis. 53(5): 369-378.

Tang, X.Y., Zhang, Y.H., Hu, M., 2006. Atmospheric Environmental Chemistry (Second Edition). Higher Education Press. Beijing. (in Chinese)

The Royal Society, 2008. Ground-level ozone in the $21^{\text {st }}$ century: future trends, impacts and policy implications. Science Policy Report 15/08. The Royal Society. London.

Wang, H.L., 2015. Characterization of volatile organic compounds (VOVs) and the impact on ozone formation during the photochemical smog episode in Shanghai, China. Acta Scientiae Circumstantiae, 35(6): 1603-1611. (in Chinese)

Wang, S., Li, G.G., Gong, Z.Y., Du, L., Zhou, Q.T., Meng, X.Y., et al. 2015. Spatial distribution, seasonal variation and regionalization of $\mathrm{PM}_{2.5}$ concentrations in China. Science China Chemistry. 58(9): 1435-1443.

Wang, X., Li, X., 1998. A numerical study of the variations and distributions of tropospheric ozone and its precursors over China. Acta Meteorologica Sinica(in Chinese). 56(3): 333-348. (in Chinese)

Wang, Z.S., Li Y.T., 2014. Temporal and Spatial Distribution Characteristics of Ozone in Beijing. Environmental Science. 35: 4446-4453. (in Chinese)

Wang, Z.Y., Ren, F.M., Wang, D.Q., Liu, Y.J., Wang, P.L. 2013. Anomalies of Ocean and Atmospheric Circulation in 2012 and Their Impacts on Climate in China. Meteorological Monthly. 39(4): 508-515. (in Chinese)

Wei, H.H, Zheng, Y.F., 2006. Analysis of the Temporal and Spatial Distributions of the Total Ozone over China. Journal of Nanjing Institute of Meteorology. 29: 390-395. (in Chinese)

Xiao, Q., Wu, R., 1995. Numerical experiments of influence of topography on atmospheric motion. Acta Meteorologica Sinica. 53(1): 38-49

Yang, C.X., Yang, H.B., Guo, S., Wang, Z.S., Xu, X.H., Duan, X.L. 2012. Alternative ozone 
metrics and daily mortality in Suzhou: the China air pollution and health effects study (CAPES). Sci. Total Environ. 426: 83-89.

Yang, S., Xu, L., 1994. Linkage between Eurasian winter snow cover and Chinese summer rainfall: different from the snow-Indian monsoon circulation. Int. J. Climatal. 14: 739-750. (in Chinese)

Yin, H.L., Yuan, H.W., Ye, Z.X., Li, S.P., Liang, J.F. 2015. Temporal and spatial distribution of VOCs and their OFP in the atmosphere of Chengdu. Acta Scientiae Circumstantiae. 35(2): 386-393. (in Chinese)

Zhang, Q., Streets, D.G., Carmichael, G.R., He, K.B., Huo, H., Kannari, A., et al. 2009. Asian Emissions in 2006 for the NASA INTEX B Mission. Atmos Chem Phys. 9: 5131-5153.

Zhang, T.H., Yin, Y., Gao, J.H., Chen, K., Xiao, H., An, J.L., et al. 2013. Characteristics and source analysis of $\mathrm{O}_{3}$ in spring and summer in high-altitude area of Eastern China. Transactions of Atmospheric Sciences. 36: 683-698. (in Chinese)

Zhang, X.Y., Wang, Y.Q., Niu, T., Zhang, X.C., Gong,S.L., Zhang, Y.M., et al. 2012. Atmospheric aerosol compositions in China: spatial/temporal variability, chemical signature, regional haze distribution and comparisons with global aerosols. Atmos. Chem. Phy. 12: 779-799.

Zhang, Y.H., Shao, K.S., Tang, X.Y., Li, J.L. 1998. Photochemical Smog Pollution in Urban China. Acta Scientiarum Naturalium Universitatis Pekinensis. 34(2 3): 392-398. (in Chinese)

Zhang, Y.H., Zhu, X.L., Slanina, S., Shao, M., Zeng, L.M., Hu, M., et al. 2004. Aerosol pollution in some Chinese cities. Pure Appl Chem. 76(6): 1227-1239.

Zhao, Y., Xu, X., Cui, C., 2012. Case study on the impact of mesoscale topography on the meiyu frontal rainstorm. Plateau Meteorology. 31(5): 1268-1282. (in Chinese) 


\section{List of tables:}

Table 1 Annual $\mathrm{O}_{3}-8 \mathrm{hr}$ concentrations in seven geographic divisions of China for 2015

\begin{tabular}{|c|c|c|c|c|c|c|c|}
\hline \multirow{2}{*}{ Division } & \multicolumn{6}{|c|}{ Annual averaged $\mathrm{O}_{3}-8 \mathrm{hr}\left(\mu \mathrm{g} \mathrm{m}^{-3}\right) 90$ percentiles of $\mathrm{O}_{3}-8 \mathrm{hr}\left(\mu \mathrm{g} \mathrm{\textrm {m } ^ { - 3 } )}\right.$} & \multirow{2}{*}{$\begin{array}{c}\text { City } \\
\text { number }\end{array}$} \\
\hline & Min. & Max. & Ave. \pm S.D. & Min. & Max. & Ave. \pm S.D. & \\
\hline North China & 56.7 & 110.8 & $84.5 \pm 15.0$ & 81.0 & 202.7 & $143.0 \pm 28.1$ & 36 \\
\hline Northeast China & 52.6 & 111.2 & $79.5 \pm 12.2$ & 90.8 & 183.2 & $129.8 \pm 24.5$ & 36 \\
\hline East China & 43.7 & 116.9 & $85.4 \pm 17.6$ & 62.6 & 197.7 & $140.6 \pm 33.0$ & 78 \\
\hline Central China & 63.2 & 107.6 & $85.1 \pm 10.8$ & 105.6 & 178.0 & $145.0 \pm 18.1$ & 44 \\
\hline South China & 48.9 & 107.6 & $79.8 \pm 11.7$ & 90.0 & 171.7 & $129.8 \pm 16.7$ & 37 \\
\hline $\begin{array}{c}\text { Southwest } \\
\text { China }\end{array}$ & 47.9 & 104.8 & $76.6 \pm 30.6$ & 75.0 & 183.0 & $120.2 \pm 23.6$ & 54 \\
\hline $\begin{array}{c}\text { Northwest } \\
\text { China }\end{array}$ & 36.9 & 118.2 & $85.2 \pm 15.0$ & 62.0 & 158.0 & $128.5 \pm 16.3$ & 53 \\
\hline
\end{tabular}


Table 2 The 12 regions identified from REOF analysis of ozone concentrations in the pollution season (May to October) of 2015

\begin{tabular}{|c|c|c|c|c|c|c|}
\hline Region & Mode & Region Name & $\begin{array}{c}\text { Variance } \\
\text { contribution } \\
(\%)\end{array}$ & $\begin{array}{l}O_{3}-8 h r \\
\left(\mu g m^{-3}\right)\end{array}$ & $\begin{array}{c}90 \text { percentiles } \\
\text { of } \mathrm{O}_{3}-8 h r(\mu g \\
\left.\mathrm{m}^{-3}\right)\end{array}$ & $\begin{array}{l}\text { City } \\
\text { number }\end{array}$ \\
\hline \multirow[b]{2}{*}{ I } & 1 & North and & 11.85 & $85.6 \pm 13.6$ & $162.5 \pm 31$ & 60 \\
\hline & 14 & $\begin{array}{l}\text { Northeast } \\
\text { China Plain }\end{array}$ & 1.63 & $69.1 \pm 7.5$ & $109.7 \pm 14.6$ & 7 \\
\hline \multirow{2}{*}{ II } & 2 & Huanghuai & 7.90 & $89.0 \pm 14.3$ & $164.6 \pm 29.2$ & 37 \\
\hline & 17 & Plain & 1.32 & $99.8 \pm 3.0$ & $164.4 \pm 9.8$ & 4 \\
\hline III & 3 & $\begin{array}{c}\text { Middle Yangtze } \\
\text { River Plain }\end{array}$ & 7.38 & $78.8 \pm 12.4$ & $148.4 \pm 23.7$ & 35 \\
\hline \multirow{3}{*}{ IV } & 4 & & 6.01 & $78.8 \pm 13.5$ & $137.3 \pm 24.6$ & 27 \\
\hline & 10 & South China & 2.06 & $79.3 \pm 8.4$ & $130.7 \pm 8.6$ & 11 \\
\hline & 13 & & 1.64 & $80.5 \pm 9.1$ & $134.4 \pm 18.2$ & 6 \\
\hline V & 5 & East China & 5.98 & $92 \pm 13.6$ & $168.4 \pm 27.3$ & 24 \\
\hline VI & 6 & Sichuan Basin & 5.82 & $81.5 \pm 15.4$ & $145 \pm 22.6$ & 22 \\
\hline \multirow{2}{*}{ VII } & 7 & & 5.81 & $77.6 \pm 15.4$ & $115.9 \pm 25.5$ & 20 \\
\hline & 12 & & 1.73 & $68.6 \pm 7.6$ & $110.6 \pm 16.9$ & 8 \\
\hline \multirow{2}{*}{ VIII } & 8 & Xinjiang & 3.13 & $78.5 \pm 16.1$ & $123 \pm 21.2$ & 12 \\
\hline & 15 & Province & 1.41 & $74.9 \pm 16.5$ & $111.1 \pm 27.5$ & 5 \\
\hline \multirow{2}{*}{ IX } & 9 & Guanzhong & 3.01 & $81.7 \pm 7.1$ & $143 \pm 13.6$ & 16 \\
\hline & 18 & Plain & 1.13 & $92.9 \pm 11.2$ & $143.2 \pm 12.5$ & 6 \\
\hline$X$ & 11 & Qiantao Plain & 1.94 & $93.5 \pm 8.1$ & $150.9 \pm 12.8$ & 8 \\
\hline XI & 16 & Tibetan Plateau & 1.34 & $87.7 \pm 14.4$ & $127.5 \pm 17.8$ & 4 \\
\hline XII & 26 & $\begin{array}{l}\text { Hainan } \\
\text { Province }\end{array}$ & 0.77 & $71.5 \pm 2.1$ & $101.9 \pm 12.5$ & 2 \\
\hline
\end{tabular}


Table 3 Pearson rank correlation coefficients between the party representative cities in the various subregions from May to October 2015

Other cities in modes

\begin{tabular}{|c|c|c|c|c|c|c|c|c|c|}
\hline & & Beijing & Zhengzhou & Changsha & Guangzhou & Shanghai & Chengdu & Kunming & Changj \\
\hline & Shenyang & 0.674 & 0.412 & -0.158 & -0.107 & -0.114 & 0.283 & 0.037 & 0.326 \\
\hline & Shangqiu & 0.272 & 0.707 & -0.009 & 0.001 & 0.135 & 0.223 & 0.038 & 0.107 \\
\hline & Xiangtan & -0.119 & -0.021 & 0.869 & 0.272 & 0.106 & -0.133 & -0.021 & -0.162 \\
\hline The & Foshan & -0.162 & -0.127 & 0.453 & 0.906 & -0.020 & -0.220 & -0.211 & -0.169 \\
\hline base & Wuxi & -0.102 & 0.076 & 0.317 & 0.131 & 0.730 & -0.014 & -0.208 & -0.059 \\
\hline \multirow[t]{4}{*}{ city } & Neijiang & 0.261 & 0.244 & 0.016 & -0.108 & 0.011 & 0.777 & 0.404 & 0.175 \\
\hline & Dehongzhou & -0.003 & 0.041 & -0.167 & -0.174 & -0.029 & 0.158 & 0.562 & -0.014 \\
\hline & Urumqi & 0.370 & 0.244 & -0.056 & 0.140 & 0.056 & 0.322 & 0.088 & 0.675 \\
\hline & Weinan & 0.238 & 0.524 & 0.136 & 0.027 & 0.127 & 0.354 & 0.043 & 0.162 \\
\hline
\end{tabular}




\section{List of figures}

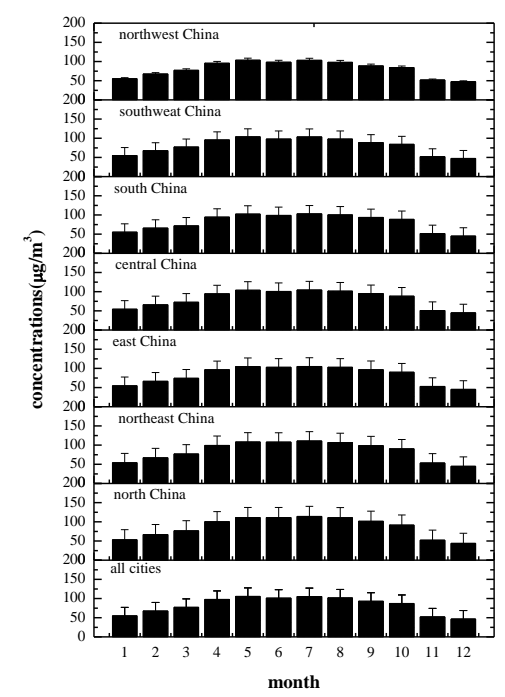

Fig. 1 Monthly averaged ozone concentrations for all cities and our seven geographic divisions of China
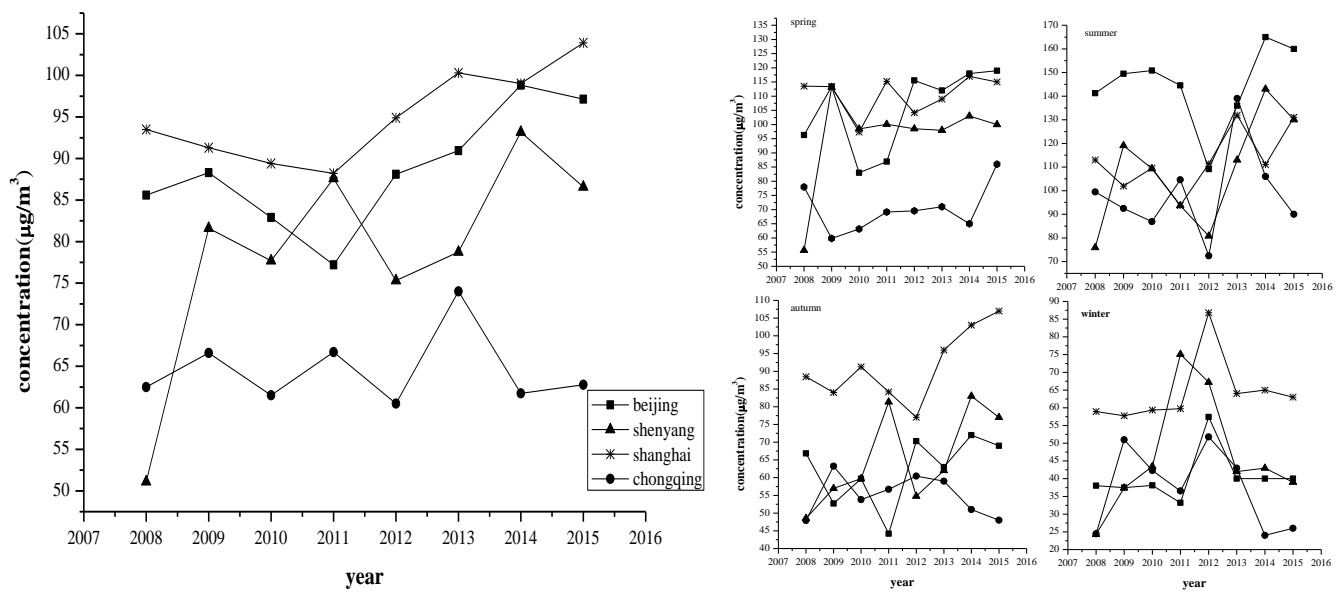

Fig. 2 Annual and seasonal ozone concentrations in Beijing, Shenyang, Shanghai, and Chongqing from 2008 to 2015 


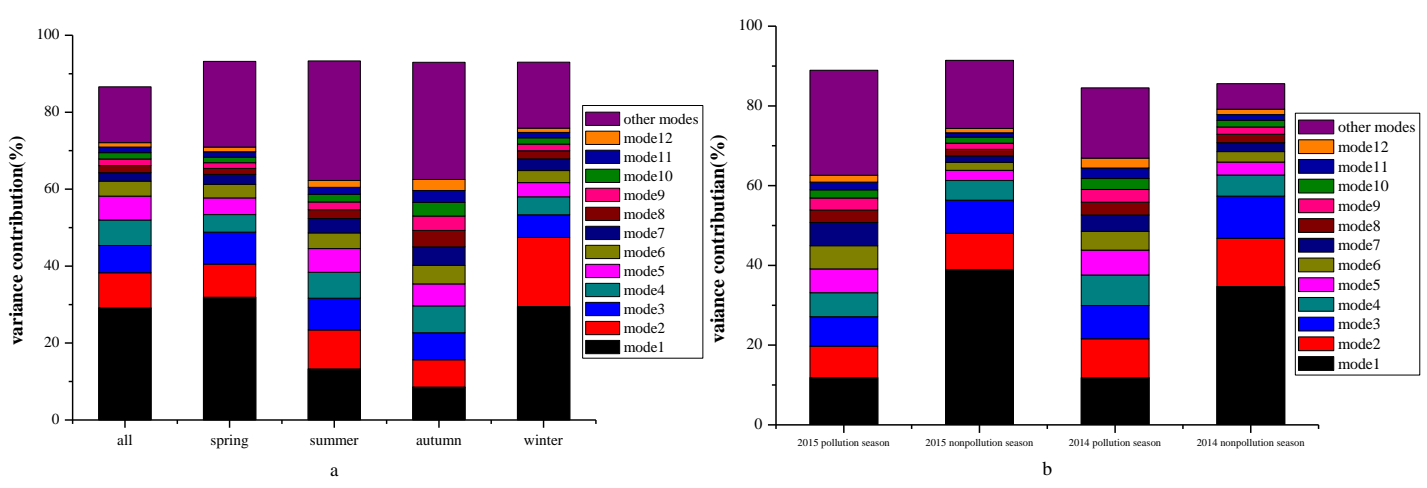

Fig.3 Variance contributions from extracted modes for total annual and seasonal datasets in 2015 (a), and pollution (May to October) versus non-pollution (November to April) seasons in 2014 and 2015 (b). The color bars represent descending variance contributions from the modes.
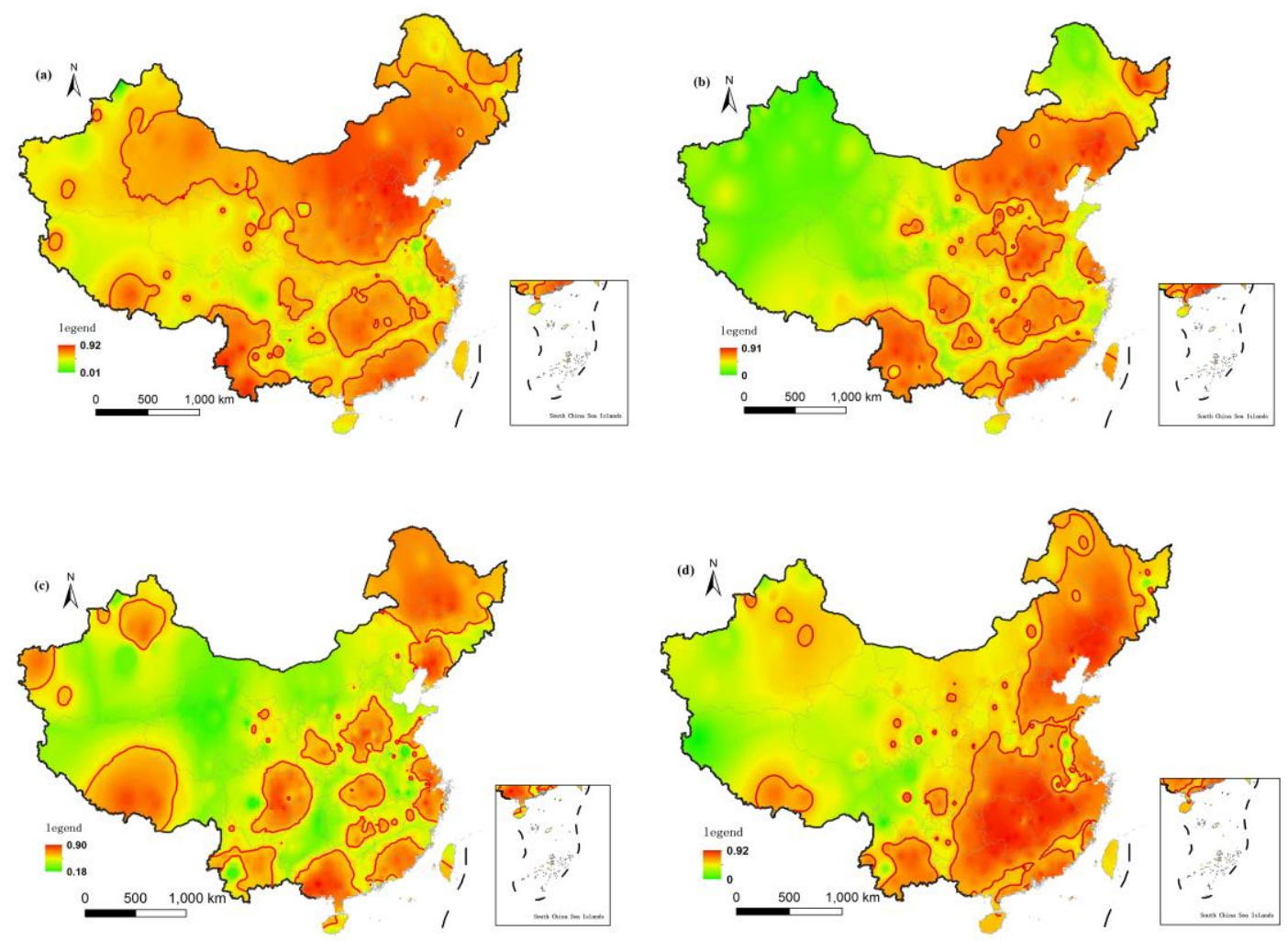

Fig.4 Spatial distributions of the modes from REOF analysis for spring, summer, autumn, and winter $(\mathrm{a}-\mathrm{d})$ based on the seasonal datasets of 338 cities in 2015: a: spring, b: summer, c: autumn, d: winter. (these merged pictures were generated by selecting the maximum loading coefficients from all modes). 

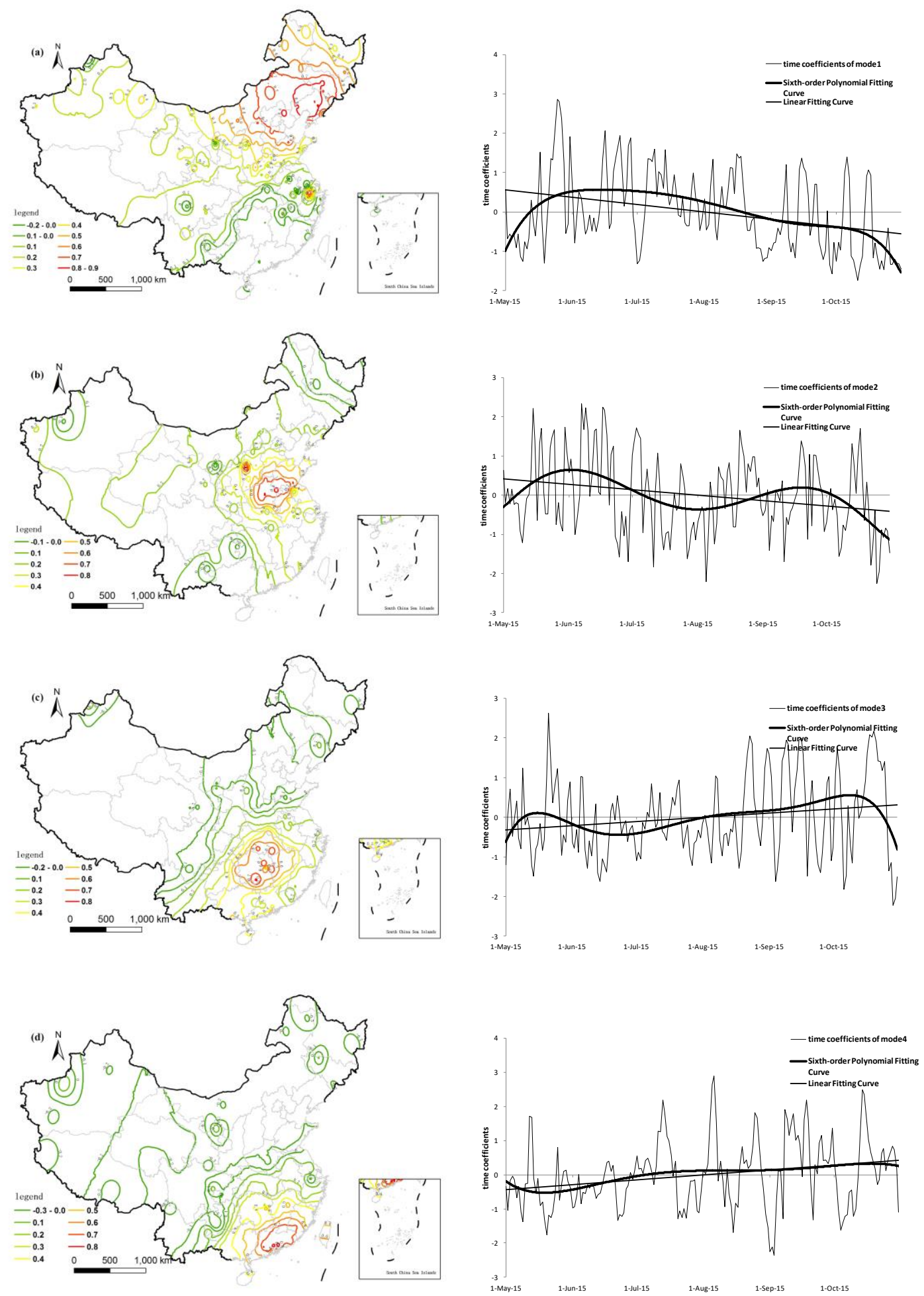

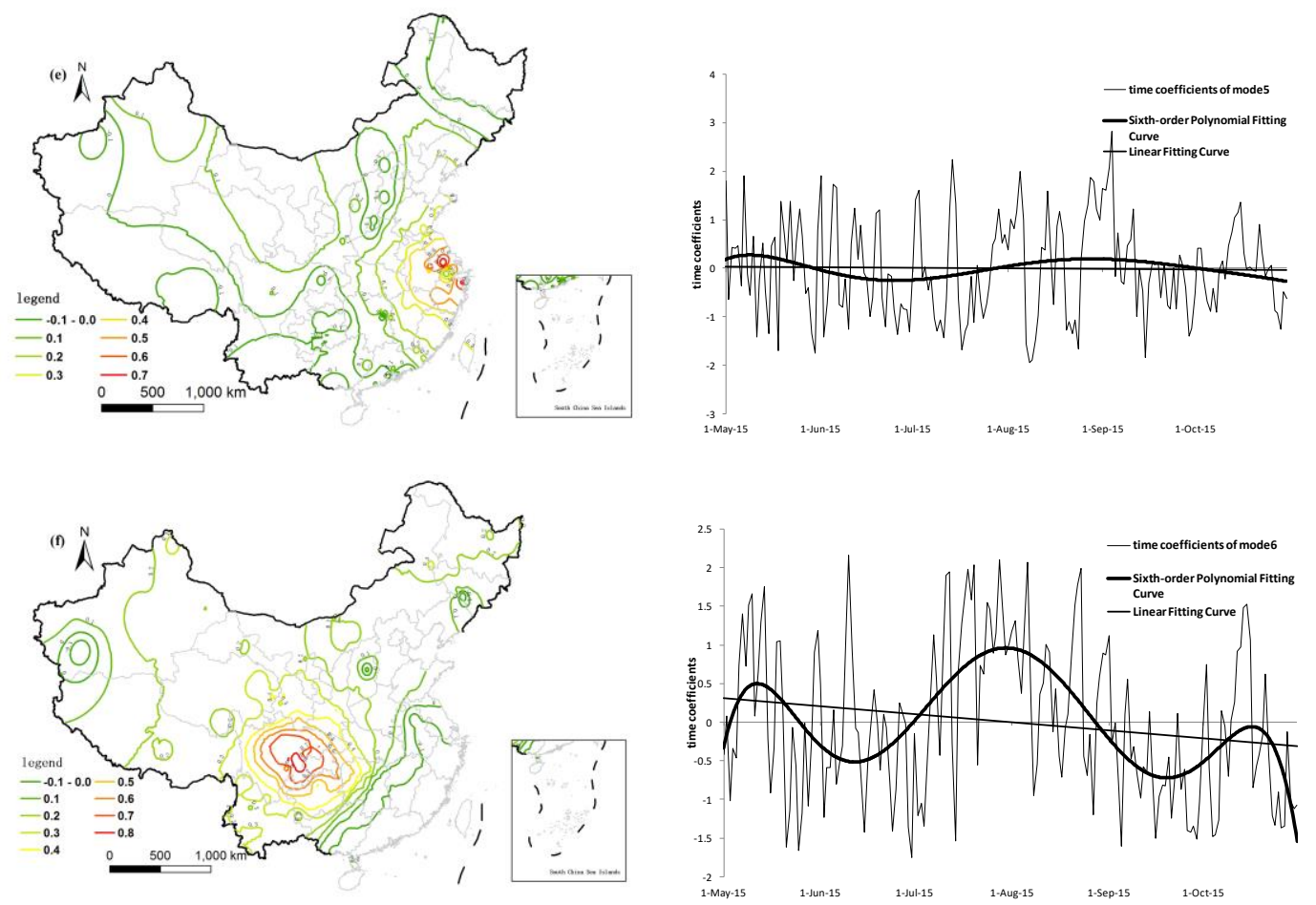

Fig.5 Spatial distributions of the top 6 modes extracted from REOF analysis for the variation of ozone in China (shown on left) and their corresponding time coefficients (shown on right)

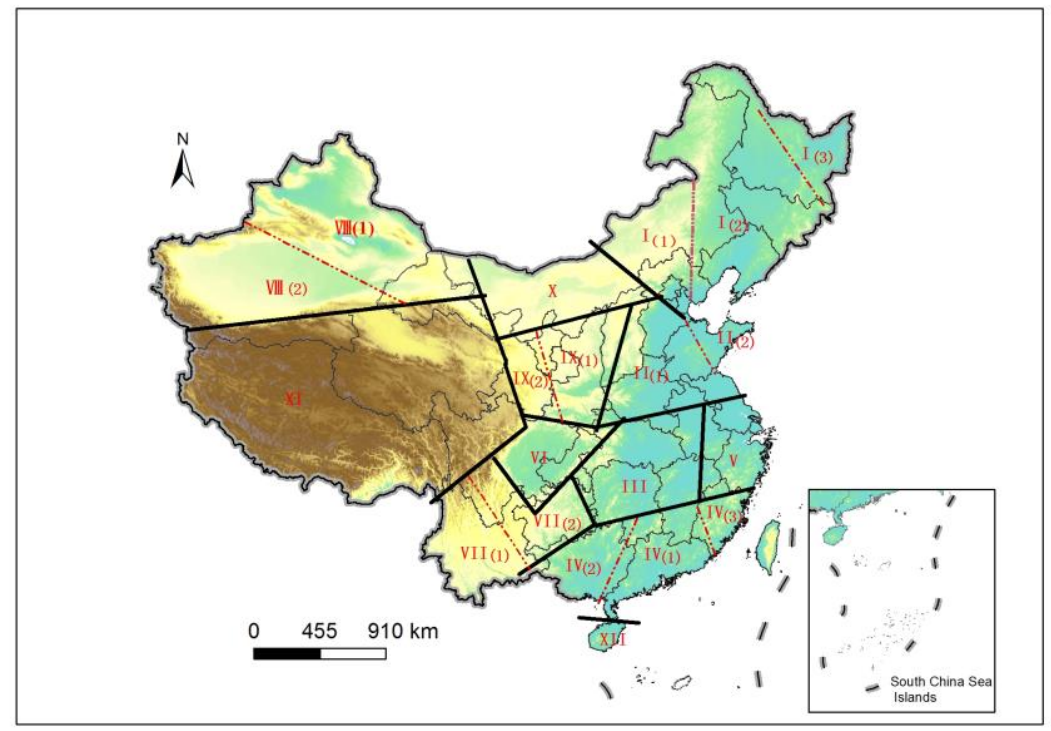

Fig.6: Regionalization of ozone in China (I: North and Northeast China Plain region, II: Huanghuai Plain region, III: Central Yangtze River Plain region, IV: South China region, V: East China region, VI: Sichuan Basin region, VII: Yungui Plateau region, VIII: Xinjiang region, IX: Guanzhong Plain region, X: Qiantao Plain region, XI: Tibetan Plateau 
region, XII: Hainan region)
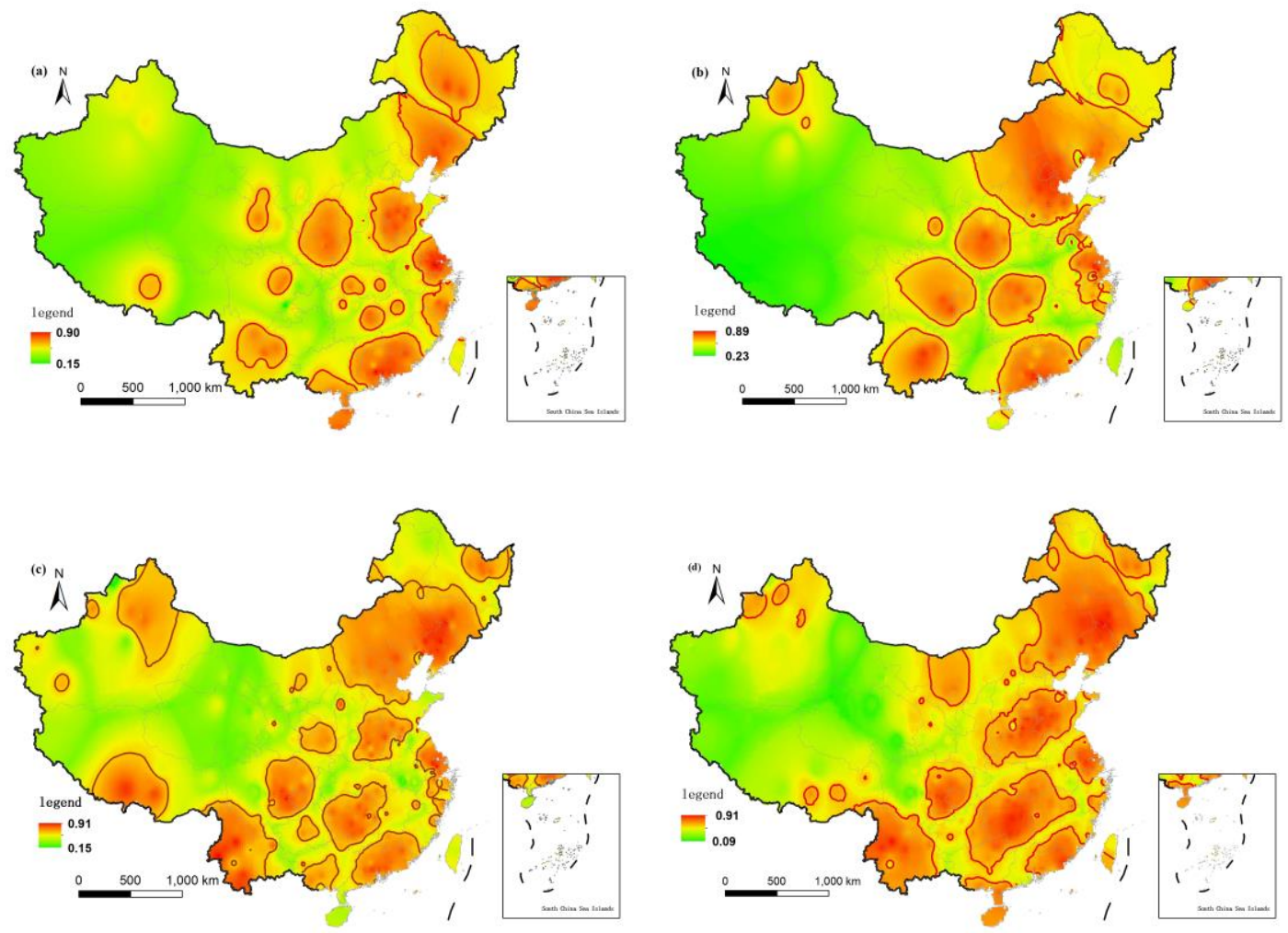

Fig.7 Spatial distributions of the modes from REOF analysis based on pollution season (May to October) datasets for 161 cities in 2014 (a) and 2015 (b), compared with 338 cities in 2015 (c) and 2016 (d)

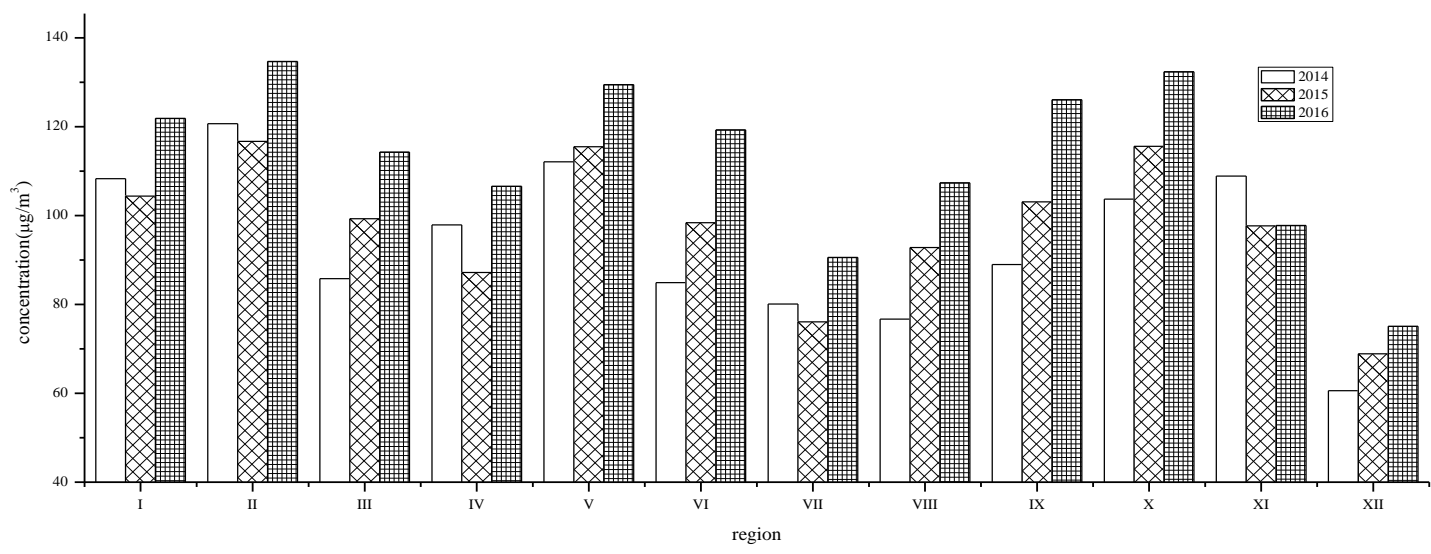

Fig. 8 The ozone concentrations in different regions for 2014 to 2016 